\title{
Bereavement among young men in prison
}

Bereavement is an inevitable part of life and learning how to cope with loss is therefore an important life skill for young people and adults alike. Worden's (1983) theory of bereavement processing outlines four tasks that must be accomplished in order to adapt to the loss: acceptance; working through the pain of grief; adjusting to the new environment without the deceased and, lastly, forming a new and appropriate bond with the deceased that allows the bereaved to move on and reinvest their emotions. Incomplete grief tasks can cause complicated or unresolved grief (Shear and Shair, 2005) which occurs when normal grief symptoms become acute and persistent and interfere with functioning. Complicated grief can result in physical symptoms and is linked to higher levels of suicidal ideation, increased risk of depression and Post Traumatic Stress Disorder (Kristjanson et al, 2006).

\section{Bereavement among the young in custody}

Young people involved in offending experience parental, multiple and traumatic deaths at a higher frequency than in the general population (Vaswani, 2008). It may be that experiencing a bereavement means that young people become less resilient and more vulnerable to negative outcomes, or simply that many of the factors associated with offending are the same as for premature death i.e. the availability of drugs and weapons (Childhood Bereavement Network, 2008). The high rates of trauma and multiple bereavements in young offenders are concerning because traumatic deaths can result in a more complicated bereavement response and multiple bereavements can cause more negative outcomes in areas such as education, depression, self-esteem and risk-taking behaviour (Ribbens McCarthy, 2005).

\section{Bereavement in the prison setting}

Given the association between bereavement and negative outcomes, it is perhaps unsurprising that bereavement is prevalent among people in custody. However, the prison setting makes dealing with bereavement more complicated as custody interferes with each of Worden's four stages of grief processing. The rate of unresolved grief is therefore likely to be higher in prison than in the general population. Unresolved grief can cause the prison significant challenges in managing behaviour, may make reintegration back in to the community more difficult to accomplish and ultimately may have an impact on reoffending rates (Childhood Bereavement Network, 2008).

Despite this association between bereavement, offending and custody there has been very little research conducted into bereavement in the prison context. To address this limitation the author conducted a study among young men in a Young Offenders Institution in order to identify the relationship between bereavement experiences and mental health symptoms and to gather young men's thoughts and views about their bereavements to enhance our understanding of their experiences. A total of 33 young men aged between 16 and 20 were surveyed about their bereavement experiences, and in-depth interviews were undertaken with a subsample of 11 young 
men. This paper represents an abridged version of the research findings and only selected elements of the young men's experiences are reported here. For further information on the methodology, mental health findings, more detailed documentation of young men's experiences and a comprehensive list of references, please see the full report (Vaswani, 2014) available in the Howard Journal of Criminal Justice.

\section{The pain of grief}

The experience of bereavement was widespread, with 30 young men (91\%) having experienced at least one bereavement, with the average around six bereavements each. Traumatic bereavements (such as those caused by murder or suicide) were common, and experienced by more than threequarters of the young men.

Sadness was the predominant response to bereavement, and recognised by many of the young men as a normal, expected and enduring emotion following a death. However, a bereavement could trigger a huge range of emotions and responses, including: excessive rumination; sleep problems; guilt; and loss of interest in activities. Anger was also a common response, particularly in situations where the death was perceived as needless, or a waste of life. In instances where murder had been committed the grief responses were sometimes complicated because the young men knew the perpetrator of the crime.

"I felt angry at the guy that killed him...for a long time, I know who it was, l've came across them a few times...not long after I came across him and all I thought was 'revenge"

However, many of the young men found that the most difficult aspect of the bereavement was not necessarily the loss itself, but rather the wider impact that the bereavement had on their life, or the far-reaching 'ripples of death'. For example, when family breakdown occurred following a bereavement this simply compounded the young men's losses.

\section{Dealing with the pain of grief}

The young men tended to adopt two distinct strategies in dealing with the pain of grief: forgetting or remembering (strategies that were avoidant or non-avoidant). Avoidant responses were commonplace, including distraction techniques such as self-medication and keeping themselves busy. Stoicism was evident among many young men, who felt it was best that they just 'get on with things', keeping a tight lid on their feelings and often displaying a dispassionate attitude towards death.

"I felt a lot of things, a lot of things I hadnae really felt before. And I didnae know how to deal with them so I just didnae deal with them. I forgot about them." 
While avoidant coping strategies may have short-term benefits, in the longer term they can prove problematic, and often led to the young men acting out their frustrations. It appeared as though many became numb and detached following a bereavement and ceased to believe in their own life or future and therefore the consequences of their behaviour. Others directly attributed the loss to their being in prison.

"I just didnae bother with anything, even the police they didn't scare me, they didn't bother me anymore"

A small minority of young men did take the approach of consciously 'remembering' by taking part in bereavement rituals such as marking the anniversary of the death. In these young men this process of 'remembering' seemed to have facilitated the task of adjustment and allowed the young men to develop and maintain a positive and appropriate connection to the deceased person, paving the way for the successful completion of Worden's tasks of mourning.

However, it was clear that the realities of prison life interrupted all aspects of the grieving process. The prison was a challenging environment in which to deal with the pain of bereavement. The dominant macho culture did not promote the display of vulnerability or weakness, and the young men tended to put on a front in order to maintain their status. In addition prison removed the young men from their social support networks, and the much employed technique of 'distraction' was affected by the restrictions and routines of daily prison life.

"Some people really try and put on a brave face, I haven't seen anyone cry [...] because you don't want to show anything like that for reputation or something like that"

\section{Bereavement rituals}

Logistical and security concerns also meant that there was reduced opportunity for participation in important bereavement rituals, such as visits to graves or occasions for shared remembering with family and friends. Even though funeral attendance was facilitated for immediate family relationships, many young men felt that attending in handcuffs showed serious disrespect to the deceased and that they would not attend in these circumstances. Others expressed frustration at what was seen as a narrow definition of family, when in reality they often had extended family networks who had played important roles in their upbringing. However, funerals offered an important outlet for young men by allowing a socially acceptable showing of grief for many who otherwise bottled up their emotions.

"I was sad, that was the only time I ever cried over her at the funeral...I think that's when I came to reality that she wouldn't be coming back...and everyone else was greeting". 
Most of the young men had not sought professional support to help them adjust to their bereavements because they wanted to deal with their bereavements in their own way. However, all young men recognised that having someone to talk to was important for other bereaved young people, even though they were certain that this style of intervention was not for them. Despite this, many young men seemed to enjoy telling the stories of their loved ones. As constructing stories about loved ones has an important role in processing grief (Bosticco and Thompson, 2005), further exploration of narrative and 'story-telling' approaches to bereavement may prove promising in encouraging participation in interventions and in improving outcomes for a vulnerable and troubled group of young men.

Nina Vaswani is Research Fellow at the Centre for Youth and Criminal Justice (CYCJ), University of Strathclyde. For more information on the centre, visit: www.cycj.org.uk

\section{$\underline{\text { References }}$}

Bosticco, C. and Thompson, T.L. (2005) Narratives and story-telling in coping with grief and bereavement. Omega, 51, No. 1, 1-16.

Childhood Bereavement Network. (2008). Bereavement in the secure setting. London: National Children's Bureau.

Kristjanson, L., Lobb, E., Aoun, S. and Monterosso, L. (2006). A systematic review of the literature on complicated grief. Available at: http://www.health.gov.au/

Ribbens McCarthy, J. with Jessop, J. (2005) Young People, Bereavement and Loss. Disruptive transitions? London: National Children's Bureau.

Shear, K. and Shair, H. (2005) Attachment, loss, and complicated grief. Developmental Psychobiology, 47, 253-267.

Worden, J.W. (1983) Grief counselling and grief therapy. London: Tavistock.

Vaswani, N (2008) Persistent offender profile: focus on bereavement. Criminal Justice Social Work Development Centre for Scotland Briefing Paper 13. Available at: http://www.cyci.org.uk/files/2014/01/Bereavement-Paper-CJSW-Briefing.pdf

Vaswani, N. (2014). The ripples of death: Exploring the bereavement experiences and mental health of young men in custody. The Howard Journal of Criminal Justice, 53(4), 341-359. 